\title{
Research of the Behavior of Consumers in the Insurance Market in the Czech Republic
}

\author{
Marešová Petra
}

\begin{abstract}
The purpose of this article is to familiarize with research aim, goal of which is to map out consumer behavior in the choice of insurance against death was carried out. This insured risk was chosen because for most insurers in the product offering as one of the key and it occurs within the highly competitive bid. At consumer behavior specification is also taken into account their classifying that can influence potential irrational behavior elements and help to clarify studied dilemma more (e.g. income brackets, age or other demographic information). Results will contribute to decision-making theory enrichment in given specific segment. From view of practice, they will be used in co-operative institution with the aim of a better client comprehension, product optimization and thereby contracts decline prevention and permanent clientele expansion.

The results of the research project showed that most consumers under the influence of certain factors act irrationally. These factors include media coverage of the causes of claims discount, offer extension of insurance coverage.
\end{abstract}

Key words: consumer, insurance, market, decision-making

\section{INTRODUCTION}

The high degree of globalization of markets, increasing competition and asymmetric information mean new challenges for the participants of the markets, and the insurance market is no exception. In the Czech Republic, the supply side of the insurance market is exposed to pressure for higher commissions for insurance intermediaries, and lower margins calculated on the product. Requirements for quality and levels of provided services increase on the demand side. Because of these new trends, the need for investment in the acquisition of knowledge capital in the consumer behavior increases in importance.

The aim of this article is to analyze consumer behavior in the choice of insurance against death. At consumer behavior specification is also taken into account their classifying that can influence potential irrational behavior elements and help to clarify studied dilemma more.

Many insurers in creating and innovating products based on the modernist mindset, which is clear and structured. Modernism assumes that autonomous systems behave according to rational economic models. According to our assumption, one of the factors affecting products demand offered is irrational consumer behavior, which the insurer does not have to count with. Knowledge which helps to identify price and offer a product to the right client, is key to achieve higher profits. Rational people should behave effectively in order of the target, which they pursue at the time of selection, which specifically means that consumers want to maximize their benefit, respectively the benefit arising from consumption, in our case services 
(Thaler, 2000). The assumption of rational behavior could be challenged for many reasons, including:

- Asymmetric informatics,

- Advertising,

- Reference group,

- Sex, age, education and income group.

Given the aforementioned potentials for distortion of rational behavior of clients, in 2010 at the University Hradec Králové a research was realized focusing on this issue. The research was conducted in collaboration with one of the most important players on the Czech insurance market. The aim of the research project was to explore consumer behavior in assumption of the offer from one type of insurance coverage (insurance in case of death) in three variants. Insurance against death was selected because it is for most insurers in the product portfolio as one of the key insurance coverage. The main question, the research sought the answer for, is whether, in the case of perfect information the consumer in insurance market behaves rationally or not, and what factors have a significant influence on their decisions.

\section{THEORETICAL BASES OF CONSUMER BEHAVIOUR AND ASYMMETRIC INFORMATION}

Consumer decision making has long been of interest to researchers. Beginning about 300 years ago early economists, led by Nicholas Bernoulli, John von Neumann and Oskar Morgenstern, started to examine the basis of consumer decision making (Richarme, 2005). This early work approached the topic from an economic perspective, and focused solely on the act of purchase (Loudon, 1993). The most prevalent model from this perspective is „Utility Theory” which proposes that consumers make choices based on the expected outcomes of their decisions. Consumers are viewed as rational decision makers who are only concerned with self-interest (Schiffman, 2007; Zinkhan, Human, 1992). Where utility theory views the consumer as a „rational economic man” (Zinkhan, Human, 1992), contemporary research on Consumer Behavior considers a wide range of factors influencing the consumer, and acknowledges a broad range of consumption activities beyond purchasing. These activities commonly include; need recognition, information search, evaluation of alternatives, the building of purchase intention, and the act of purchasing, consumption and finally disposal. This more complete view of consumer behavior has evolved through a number of discernible stages over the past century in light of new research methodologies and paradigmatic approaches being adopted.

While this evolution has been continuous, it is only since the 1950's that the notion of consumer behavior has responded to the conception and growth of modern marketing to encompass the more holistic range of activities that impact upon the consumer decision (Blackwell, 2001). This is evident in contemporary definitions of consumer behavior: "consumer behavior...... is the study of the processes involved when individuals or groups select, purchase, use or dispose of products, services, ideas or experiences to satisfy needs and desires" (Solomon, 2006). In a further development of this issue, models of consumer behavior have been created. For example a model of rational, sociological, or frame model (Koudelka, 2006). 
Within consumer decision-making, what information is available for them is crucial. This area counts that on the supply and demand sides is influencing the decision, due to the so-called "asymmetric information". The asymmetric information represents a situation where economic entities on one side of the market, have better information than entities on the other side. The entities can use or abuse the better information, which may cause damage to other market participants. Thanks to this, the so-called market failures occur, when in theory, an effective market mechanism will behave inefficiently, distorted prices and other market parameters will occur. Thanks to the above-mentioned work with the risk, in insurances the asymmetric information has a significant impact on the functioning of the insurance market. On one hand, it is obvious that entities having an interest in concluding insurance are better aware of their situation than an insurance company and might even intentionally place false information on the situation; on the other hand, the insurance company may have better information thanks to the large number of clients and claims which they deal with. Also, the insurance company usually has better information about the self-constructed product (Marešová, Drahokoupil, 2001).

The advantage of the demand side is the advantage of the client of the insurance company. The advantage lies in the fact that nobody knows their own situation, health condition, technical condition of assets, financial situation, etc. better than the clients themselves who want to be insured. Such a client should therefore logically conclude insurance whenever they think its worthy, i.e. the rate of their future benefit will be higher than if they did not conclude insurance. The client uses their dominance in the information, assuming that the insurance company will pay them more than they pay to insurance company (Marešová, Drahokoupil, 2001).

Analogy of an individual economic decision-making entity, whether to get insured or not, is the decision-making of the insurance company regarding the insurance premium. However, while for an individual economic entity, as it has been said, this is a subjective matter, in the case of insurance company, given the large number of clients and claims, it is rather a mathematical problem solving through exploration of the collective phenomena. In this, an informational advantage can be seen on the insurance company side, when the insurance company may in its deliberations use the historic statistical ensemble of clients, insurance claims and events and from that, they can guess the future development of currently concluded insurances. Due to the size of the statistical ensemble, it is obvious and possible to use the law of averages for the mutual balancing of risks, as well as other work with risk. Insurance companies on the basis of historical data and other obtained information, create a calculating model of insurance premium, which they adjust at the time. According to Daňhel (Daňhel, 2006), thanks to the above-mentioned, there is clear information prevalence on the insurance company side.

In the decision-making field, a large number of studies have been implemented. These include, for example, consumer behavior in the selection of banking products in Pakistan. Table 5 shows the results of research objective two and three with the help of Marginal effect of sensitivity analysis. It is significant at 0.05 level of significance The seven influencing factors are rank from the factor analysis and the logistic regression model is ranked as follows: 
Tab. 1 - Marginal Effects of Customers Switching Behavior. Source: (Khan, Ghouri, Siddqui, Shaikh, Ala, 2010)

\begin{tabular}{|c|c|}
\hline Ranking Factors Name & Marginal effect \\
\hline 1 Price & 0.16398341 \\
\hline 2 Distance & 0.10936621 \\
\hline 3 Switching Cost & -0.10567336 \\
\hline 4 Service Quality & 0.07095342 \\
\hline 5 Reputation & 0.06339969 \\
\hline 6 Involuntary Switching & -0.05280674 \\
\hline 7 Effective Advertising Competition & 0.04025589 \\
\hline
\end{tabular}

The marginal effects table illustrates that price factor making the maximum impact on customers bank switching behavior in retail banking of Pakistan. The results show that a unit increase in price results $16.4 \%$ probability that a customer will switch banks. Price has the second highest impact maker on customers bank switching behavior. A unit increase in the Distance factor (eg. branch close) results in $10.93 \%$ probability of customers switching banks. $10.56 \%$ is probability of customer switching in retail banking industry of Karachi, if one unit of Switching Cost decreases. Similarly, Service Quality, Reputation, Involuntary Switching and Effective Advertising Competition are the fourth, fifth, sixth and seventh important factors that impact customers retail bank switching behavior of Pakistan (see Table 1).

Further research in the field of banking analyzed the decision-making of clients with regard to the quality of services provided (Ravichandran, Bhargavi, Kumar, 2010). The above equation shows the impact of the variables of service quality aspects such as convenient operating hours, modern looking equipment, bank understand the specific needs of customer, banks frontline employees are neat appearing. On an average if the modern looking buildings and amenities change by 1 unit, there will be 0.135 units increase in the overall behavioral intention when other variables are kept constant.

A similar analysis of consumer behavior, focusing on financial services, has been implemented in Portugal. There have also been investigated and identified the factors determining the choice of a product (Proença, Rodrigues, Amorim, 2009).

\section{METHODOLOGY}

Within the analysis, the method of "test of independence in contingency table" was used. Under this method, a file is considered, divided according to two statistical features into r groups by first character, and s groups according to the second character. On the basis of a random selection of $n$ size, independence of these two statistical characters are tested. When the validity of the hypothesis of independence, the frequency of individual variants $n_{i j}$, for $i=\{1,2 \ldots$ $r\}, j=\{1,2 \ldots s\}$ correspond with the values of expected frequency calculated according to the relation (Budíková, Králová, Bohumil, 2010). 


$$
n_{i j}^{\prime}=\frac{\sum_{i=1}^{r} n_{i j} \sum_{j=1}^{s} n_{i j}}{\sum_{i=1}^{r} \sum_{j=1}^{s} n_{i j}}
$$

The test of independence in the contingency table, can be considered credible, if the nij expected frequency of occurrence exceeds a value of 5 in at least $80 \%$ of each group and each of the expected frequency is higher than value 1 (Budíková, Králová, Bohumil, 2010). The following hypothesis is tested:

$H_{0}: n_{i j}=\frac{n_{i \bullet} n_{\bullet}}{n} \quad$ For all $\mathrm{i}=\{1,2, \ldots, \mathrm{r}\}$

$H_{A}: n_{i j} \neq \frac{n_{i \bullet} n_{\bullet}}{n} \quad \mathrm{j}=\{1,2 \ldots \mathrm{s}\}$ for some $i, j$, where expected frequency $n_{i j}$ are

$n_{i j}^{\prime}=\frac{n_{i} n_{\bullet} j}{n} k d e \quad n_{i \bullet}=\sum_{j=1}^{s} n_{i j} \quad$ a $n_{\bullet j}=\sum_{i=1}^{r} n_{i j}$

As a test criterion the following statistics are used:

$$
G=\sum_{i=1}^{r} \sum_{j=1}^{s} \frac{\left(n_{i j}-n_{i j}^{\prime}\right)^{2}}{n_{i j}^{\prime}}
$$

Statistics $G$ has a $\chi^{2}$ distribution with $d f=(\mathrm{r}-1)(\mathrm{s}-1)$ degree of freedom. The critical value will be found by using an Excel spreadsheet, where CHIINV ( $\alpha$, df) statistical function will be used. The formula for the critical value is $\chi^{2}{ }_{1-\alpha, \mathrm{df}}$. Null hypothesis is not refused under condition:

$G \leq \chi_{1-\alpha ;(r-1)(s-1)}^{2}$

Fisher's exact test is a statistical test used to determine if there are nonrandom associations between two categorical variables (Weisstein, 2012).

Let there exist two such variables $X$ and $Y$, with $m$ and $n$ observed states, respectively. Now form an $m X n$ matrix in which the entries $a_{i j}$ represent the number of observations in which $x=i$ and $y=1$. Calculate the row and column sums $R_{i}$ and $C_{i}$, respectively, and the total sum

$$
N=\sum_{i} R_{i}=\sum_{j} C_{j}
$$

of the matrix. Then calculate the conditional probability of getting the actual matrix given the particular row and column sums, given by

$$
P=\frac{\left(R_{1} ! R_{2} ! \ldots R_{m} !\right)\left(C_{1} ! C_{2} ! \ldots C_{m} !\right)}{N ! \Pi_{i j} a_{i j} !}
$$


which is a multivariate generalization of the hyper geometric probability function. Now find all possible matrices of nonnegative integers consistent with the row and column sums. For each one, calculate the associated conditional probability using (6), where the sum of these probabilities must be 1 .

To compute the P-value of the test, the tables must then be ordered by some criterion that measures dependence, and those tables that represent equal or greater deviation from independence than the observed table are the ones whose probabilities are added together. The test is commonly applied to matrices. When $P$ - values $<0,05$, there would be a statistically significant association between two variables.

\section{CONSUMER DECISION-MAKING IN THE FIELD OF INSURAN- CE PRODUCTS IN THE CZECH REPUBLIC}

In 2010, in the University of Hradec Kralove in co-operation with a major insurance company in our market, research focusing on the issue of consumer behavior in the choice of insurance against death was carried out. As already mentioned, this insured risk was chosen because for most insurers in the product offering as one of the key and it occurs within the highly competitive bid. The target group was clients of co-operating organization in the age from 30 to 40 years. Clients were first alerted by correspond form that they will be addressed in the research. Then they were asked by telephone interview, which was ensured by co-workers from call a center company. The responses were recorded in a database created. 640 clients of co-operating organization were contacted, and 501 complete responses were obtained, which equals to a $78 \%$ success rate.

The questions from the survey were divided into three areas. In the first area was to determine selected characteristics of respondents such as sex, age, educational attainment, occupation (self-employed or employee), children (yes, no), an insurance in case of death (yes, no). From the selected characteristics was also prepared a price of insurance for each client according to the calculations of actuaries of co-operating institution. This price was given for each option offered in the questions below.

The second area specified a question for selection (question no. 8) in the event of death, and what is for a client determining in the choice (question no. 9).

Question no. 8: Imagine that you want to get insured in the event of your death. You can choose from three options, which differs in the scope of insurance coverage, the insured amount and the amount of the price, which has to be paid per month for insurance.

a) insurance against accidental death

Information on insurance claims

In the event that an insured event occurs due to an accident, the insurer shall pay indemnity. 
b) insurance against accidental death with double performance in the event of a traffic accident and insurance against sudden death (heart attack, stroke)

Information on insurance claims

In case the insured event (death) occurs due to accident, the insurer shall pay indemnity, if the insured event (death) occurs in a traffic accident, the insurer pays twice more.

In case the insured event (death) occurs on the leading causes of death, therefore heart attack and stroke, the insurer pays the agreed amount.

c) insurance against death

Information on insurance claims

In case the insured event (death) occurs from any cause, the insurer pays the agreed amount.

The amount of offered insurance benefits and the cost of various options were calculated for age groups and sex by actuaries of the co-operating organization.

Question no. 9: What was decisive for you in the choice of insurance options?

a) price be extent of insurance

b) the amount of insurance coverage

The last part of the questionnaire was aimed to change the client's choice in the case of replacement of options offered due to discount and change in the scope and insurance benefits. The aim was to determine, whether the extension of insurance coverage about one disease or offering discount would mean that consumer would behave differently in the decision, i.e. irrationally.

Question no. 10: In the event that the option b) ie insurance against accidental death with double performance in the event of traffic accident + insurance in case of sudden death (heart attack and stroke) would be extended by cancer, ie insurance against sudden death would be a heart attack, stroke and cancer, would you choose this option?

a) Yes I would change my decision

b) I would not change my decision

Question no. 11: In the event that you would be offered a 5\% discount when choosing option b), ie insurance in case of accidental death with a double performance in the event of traffic accident + insurance in case of sudden death (heart attack, stroke), would you choose this option?

a) Yes I would change my decision

b) I would not change my decision

This enabled structure of questions helped to specify the circumstances and factors affecting consumer decisions on insurance against death. In an analysis of factors influencing the decision of the respondents were tested hypotheses: 
HO:The choice of insurance against death is independent due to the income of a client.

H1:The choice of insurance against death is independent due to gender of a client.

H2: The choice of insurance against death is independent due to the level of education of a client.

H3: The decision about changing the variation of insurance in relation to discount of the product does not affect the original rational (option C) or irrational option (option A) of the client.

H4: The decision about changing the variation of insurance in relation with changing the scope of insurance benefits does not affect the original rational (option C) or irrational option (option A) of the client.

H5: Irrational consumer choice in the case of perfect information is independent of the client's gender.

H6: Irrational consumer choice in the case of perfect information is independent of client level of education.

\subsection{Analysis of respondents' answers}

Within the researched project was a defined circumstance by co-insurance, defining rational and irrational behavior of consumers in their choice of three options offered. It implies that consumer in the transfer of risks to the insurer may consider the offer by three parameters:

- The extent of insurance coverage (for what is insured and what not $=$ exclusions from insurance),

- The amount of insurance coverage (the maximum monetary amount provided by insurer when the insured event),

- Price (the amount of cash given by consumer to insurer to create insurance technical reserves).

Rationally behaving consumer:

- chooses a bid which ensure transfer of full range risk to insurer, i.e. the extent of insurance coverage closely resembles a insurant against risk. Option C provides 100\% coverage range for both men and women. Option B offers a range of 34\% coverage for men and $17 \%$ for women. Option A offers a range of $32 \%$ coverage for men and $15 \%$ for women,

- chooses a level of insurance performance, which is sufficient to eliminate results from the realized risk,

- takes into account cost factors for comparison of the advantages of offers from various insurers. (In this research, which offered insurance against death, it was the offer of one insurer and the consumer had a choice of three possible variants of this offer. Price does not in the case of rational behavior any effect).

- voted for the option $\mathrm{C}$, which offered the widest range of insurance coverage,

- would not vote for option B, which offered twice of the performance compared to variant $\mathrm{C}$, since the scope of insurance coverage would be significantly reduced and insurance would not fulfill its intended fiction. 


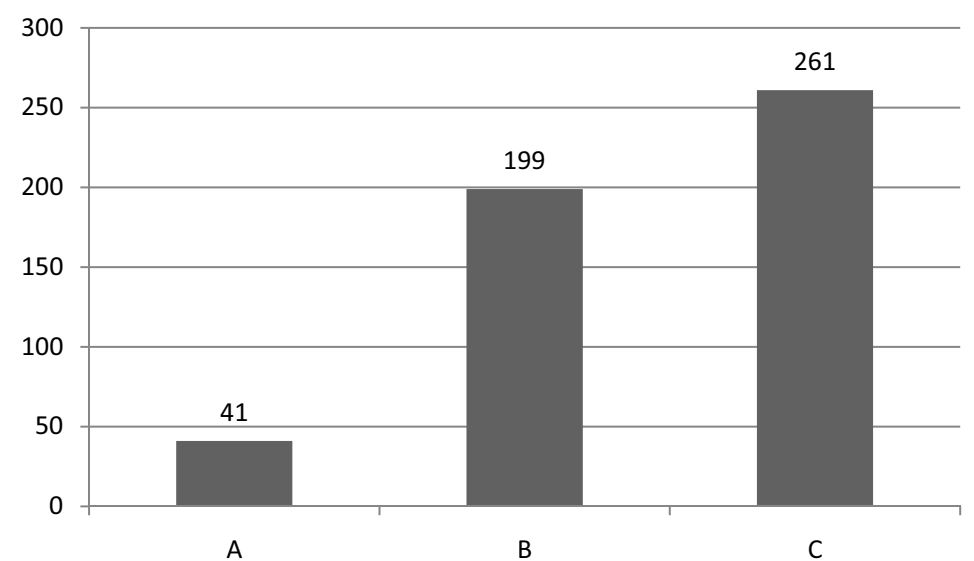

Fig. 1 - Client's decision on the choice of options. Source: author

The figure 1 clearly shows that regardless of any further dividing of clients, response $\mathrm{C}$ is predominant, which is insurance against death from any cause. This option is specified as a rational choice. We can say that most clients in the first stage of the decision process behaved rationally. Irrational choice, i.e. option A and B were voted by together 240 respondents, which is not a negligible number. The reasons for their choices will be analyzed further in testing hypotheses.

\subsection{Factors influencing the choice of insurance}

The question about the factor affecting the choice of insurance is shown in figure 2. Clients, who have opted for insurance only against accidental death, took the price as the main criteria. Clients requiring a double payment in the event of an accident (option B) took a substantial range of insurance, just as those who want to insure against death from any cause (option C). At the same time the amount of insurance coverage was the most important for those who voted for twice of the performance in case of an accident (option B).

Another aim of the questionnaire was to find out what circumstances would lead clients to change the decision (chart 3). Clients who have stated that the decisive factor in selecting was a range of insurance and also chose a rational option $\mathrm{C}$, has been offered to extend the scope of insurance coverage. I.e. insurance against accidental death with double performance in case of accident, and insurance against sudden death (heart attack and stroke) has been extended to cancer. 


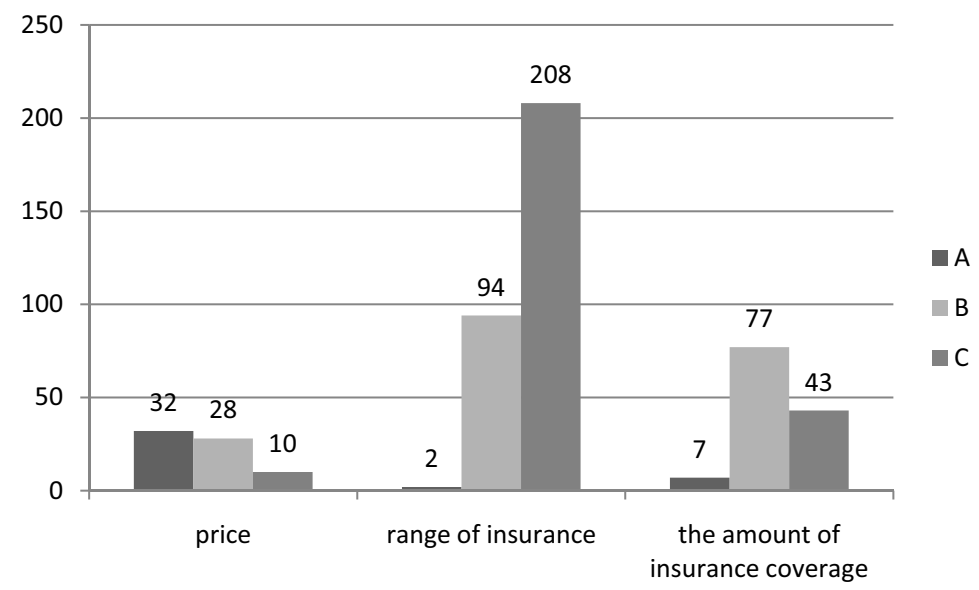

Fig. 2 - Decisive factor in the choice of insurance due to the selected option. Source: author

Tracking the movement of the preferences of rational choice in the first stage of the decision process to choose irrational. In case that a client would have as a decisive factor the price, then they got offered a discount of $5 \%$ of the price of option B. The number of clients who would change the decision is shown in figure 3. The number of clients who initially voted for option A or $\mathrm{C}$ and now they decide otherwise, that's in Figure. This graph shows that most clients would not change the decision. This applies in particular to those who voted for insurance in case of death from any cause. These clients prefer a broad range of insurance cover against the discount, or twice the performance

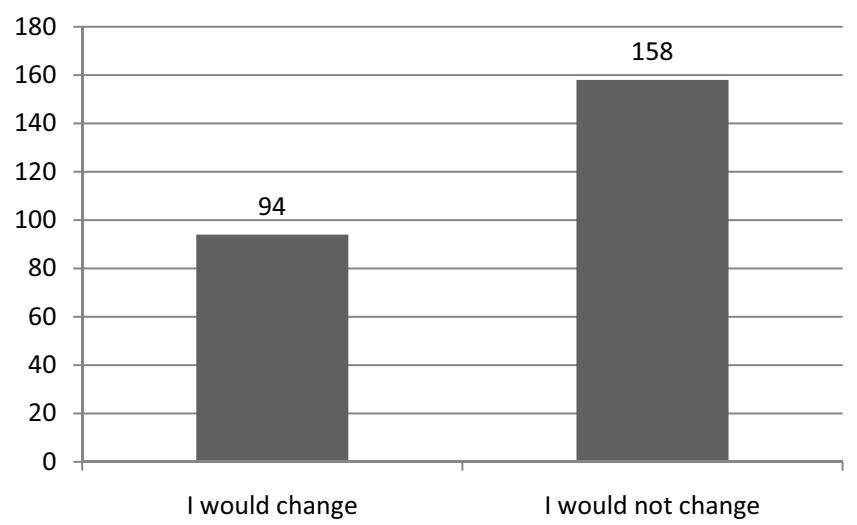

Fig. 3 - Number of clients who would change the decision on the variant B. Source: author 
The last chart shows the reason for the change option (Figure 4). 85 clients would change their choice because of changes in the scope of insurance coverage, and 11 clients because of the price. If you add to the number of people opting for option B, those who changed their minds, the percentage of those who make decisions rationally and irrationally as follows: $35 \%$ decided rationally and 65\% irrationally (opt. A + opt. B). We can say that when choosing insurance for death, most clients did not vote for the option with a full range of insurance coverage (table 1). Which means that in conditions of complete information they did not decide so that they are fully covered, therefore the decision is irrational?

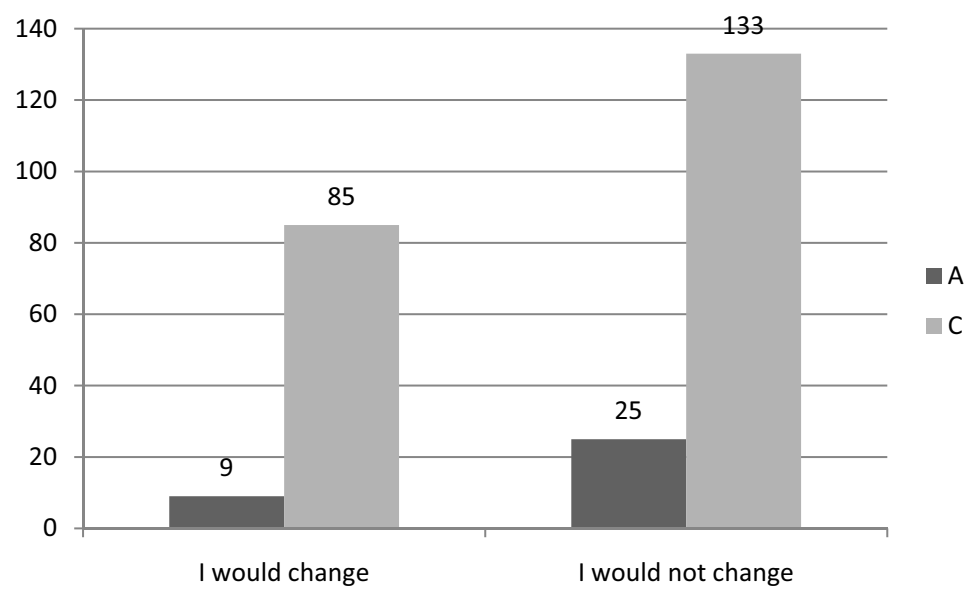

Fig. 4 - Number of clients who would be willing to switch to option B in relation to the initial choice of option. Source: author

Tab. 2 - Recapitulation. Source: author

\begin{tabular}{|l|c|c|c|c|}
\hline & A & B & C & Total \\
\hline Initial decision & 41 & 199 & 261 & \\
\cline { 1 - 4 } Change of decision for opt. B & 9 & & 85 & \multirow{2}{*}{501} \\
\cline { 1 - 3 } New decision & 32 & 293 & 176 & \\
\cline { 1 - 4 } Made in \% & 6 & 58 & 35 & \\
\hline
\end{tabular}

The aim of the research conclusion is to confirm or disprove the following hypotheses characterized, and thus acquire the necessary information about the selected circumstances of the option variant of insurance against death. As a theoretical basis to determine the range of hypotheses are used models of consumer behavior. Characterized hypothesis can be divided into three basic groups. The first one is the hypothesis testing the independence of the choice of insurance options offered on selected social factors:

HO:The choice of insurance against death is independent due to the income of a client.

H1:The choice of insurance against death is independent due to gender of a client.

H2: The choice of insurance against death is independent due to the level of education of a client. 
The second groups of hypotheses are those related to the rational model of consumer behavior (Thaler, 2000). So the main objective is to determine whether in the case of perfectly information, a consumer decides rationally. This fact will be inferred from the following hypotheses:

H3: The decision about changing the variation of insurance in relation to discount of the product does not affect the original rational (option C) or irrational option (option A) of the client.

H4: The decision about changing the variation of insurance in relation with changing the scope of insurance benefits does not affect the original rational (option C) or irrational option (option A) of the client.

Hypothesis No. 3 and No. 4 are based on the last two questions in the survey, where customers are offered discounts or expanding insurance coverage.

The latest range of hypotheses is those that specify the circumstances of the choice of irrational option of product (the chosen options A and B) in relation to selected social factors.

H5: Irrational consumer choice in the case of perfect information is independent of the client's gender.

H6: Irrational consumer choice in the case of perfect information is independent of client level of education

H0: The choice of insurance for accidental death is independent due to income of a client.

Tab. 3 - Selecting the insurance in case of death divided by payment. Source: author

\begin{tabular}{|c|c|c|c|c|c|c|c|}
\hline & Up to15 & Over 40 & $\begin{array}{c}\text { From } \\
\mathbf{3 5 - 4 0}\end{array}$ & $\mathbf{3 0 - 3 5}$ & $\mathbf{2 5 - 3 0}$ & $\mathbf{2 0 - 2 5}$ & $\mathbf{1 5 - 2 0}$ \\
\hline A & 18 & 2 & 1 & 3 & 1 & 8 & 7 \\
\hline B & 43 & 21 & 16 & 13 & 26 & 36 & 44 \\
\hline C & 73 & 40 & 14 & 11 & 37 & 32 & 55 \\
\hline
\end{tabular}

Given that in the table 3 are not all values greater than five (which is appropriate to the notice value of chi-square test) will be further tested respondents' answers in three income groups where this condition is met (table 4).

Tab. 4 - Shorter allocation. Source: author

\begin{tabular}{|c|c|c|c|}
\hline & Up to $\mathbf{1 5}$ & $\mathbf{2 0 - 2 5}$ & over $\mathbf{4 0}$ \\
\hline A & 18 & 8 & 6 \\
\hline B & 43 & 36 & 21 \\
\hline C & 73 & 32 & 40 \\
\hline
\end{tabular}

Tab. 5 - The results of testing and test criteria. Source: author

\begin{tabular}{|l|l|}
\hline The level of significance & $\alpha=0,05$ \\
\hline Test criteria & $\chi^{2}=10,2754$ \\
\hline Table value & $\chi^{2} 0,05(4)=9,49$ \\
\hline
\end{tabular}

Based on the resulting test criteria $\chi^{2}=10,2754$ on independence, $\mathrm{H} 0$ is not confirmed (table 5). This means that the choice of insurance against death is associated with the income group to which the client is included. The structure of data in the table shows that customers be- 
longing to the lowest and highest income groups mentioned would vote for option $\mathrm{C}$ and the remaining respondents option $\mathrm{B}$.

H1: The choice of insurance for accidental death is independent in a view of gender.

Based on the outcome of the test criteria $\chi^{2}=3.2147$ of independence, H1 is confirmed. This means that the choice of insurance for accidental death is independent of whether the client is male or female (table 6). The fact that the decisions do not differ in relation to gender can be attributed to the same information and equal education (table 7).

Tab. 6 - Selecting the insurance in case of death divided by gender. Source: author

\begin{tabular}{|c|c|c|}
\hline & male & female \\
\hline A & 22 & 19 \\
\hline B & 109 & 91 \\
\hline C & 121 & 140 \\
\hline
\end{tabular}

Tab. 7 - Results of testing and test criteria. Source: author

\begin{tabular}{|l|c|}
\hline The level of significance & $\alpha=0,05$ \\
\hline Test criteria & $\chi^{2}=3,2147$ \\
\hline Table value & $\chi^{2}(2)=5,991$ \\
\hline
\end{tabular}

Analogically based on the final test about independence also the H3 was confirmed. This means that the choice of insurance against death has nothing to do with the amount of klient education (table 8).

Tab. 8 - Distribution of respondents by education. Source: author

\begin{tabular}{|c|c|c|c|}
\hline Education & male & female & Total \\
\hline Secondary & 173 & 167 & 340 \\
\hline Higher & 36 & 47 & 83 \\
\hline Primary & 42 & 36 & 78 \\
\hline total & 251 & 250 & 501 \\
\hline
\end{tabular}

H3: The decision on changing the variation of insurance, in relation to discount of the product is not affect by the original rational (option C) or irrational option (option A) of the client.

Tab. 9 - Respondents' interest in change. Source: author

\begin{tabular}{|l|c|c|}
\hline & I would change & I would not change \\
\hline A & 7 & 25 \\
\hline C & 4 & 6 \\
\hline
\end{tabular}

These data would not be suitable for analysis by a chi-squared test, because the expected values in the table are lower than 5. This is the reason, why the Fisher test will be used. The results of Fisher test are in the table 10. 
Tab. 10 - The results of testing and test criteria. Source: author

\begin{tabular}{|c|c|}
\hline One sided $\mathbf{p}$-values: for $\mathbf{p}(\mathbf{O}>=\mathbf{E})$ & Two sided $\mathbf{p}$-values $\mathbf{p}(\mathbf{O}>=\mathbf{E} \mid \mathbf{O}<=\mathbf{E}):$ \\
\hline $\mathrm{p}(\mathrm{O}>=\mathrm{E}): 0.2294144^{*}$ & $\mathrm{p}=0.4102661 *($ sum of small $\mathrm{p}$ 's $)$ \\
\hline $\mathrm{p}(\mathrm{O}>\mathrm{E}): 0.0642889$ & $\mathrm{p}=0.1651255$ (left + right-exact $)$ \\
\hline mid-p: 0.1468517 & $\mathrm{p}=0.2937034$ (left + right $)$ \\
\hline
\end{tabular}

At 0,05 level of significance, it would conclude that the distribution in the observed table cannot be said to be significantly different from chance. H3 is confirmed (table 10). This means that the decision to change the choice of insurance in option at a discount is independent of whether the client initially chose rationally (option C) or irrationally (table 8) (option A).

H4: The decision on changing the variation of insurance, in relation to changing the scope of insurance performance is not affect by the original rational (option $\mathrm{C}$ ) or irrational option (option $\mathrm{A}$ ) of the client.

Tab. 11 - Respondents' interest in change. Source: author

\begin{tabular}{|l|c|c|}
\hline & I would change & I would not change \\
\hline A & 2 & 0 \\
\hline C & 81 & 27 \\
\hline
\end{tabular}

These data would not be suitable for analysis by a chi-squared test, because the expected values in the table are lower than 5. This is the reason, why the Fisher test will be used. The results of Fisher test are in the table 12.

Tab. 12 - The results of testing and test criteria. Source: author

\begin{tabular}{|c|c|}
\hline One sided $\mathbf{p}$-values: for $\mathbf{p}(\mathbf{O}>=\mathbf{E})$ & Two sided $\mathbf{p}$-values $\mathbf{p}(\mathbf{O}>=\mathbf{E} \mid \mathbf{O}<=\mathbf{E}):$ \\
\hline $\mathrm{p}(\mathrm{O}>=\mathrm{E}): 1 *$ & $\mathrm{p}=1 *($ sum of small $\mathrm{p}$ 's $)$ \\
\hline $\mathrm{p}(\mathrm{O}>\mathrm{E}): 0.4323603$ & $\mathrm{p}=0.5676397$ (left + right - exact $)$ \\
\hline mid-p: 0.7161802 & $\mathrm{p}=0.4323603($ left + right $)$ \\
\hline
\end{tabular}

At 0.05 level of significance, it would conclude that the distribution in the observed table cannot be said to be significantly different from chance.H4 is confirmed (tab. 12). This means that the decision to change the choice of insurance when you change the scope of insurance coverage is independent of whether the client initially chose rationally (option C) or irrationally (A option) (Tab. 11).

Result of hypotheses $\mathrm{H} 3$ and $\mathrm{H} 4$ refutes the assumption that the autonomous systems, which decide rationally after the change of the parameters of the offer, will rationally decide again.

H5: Irrational consumer choice in the case of perfect information is independent of the client's gender. 
Tab.13 - Selecting the insurance in case of death divided by gender. Source: author

\begin{tabular}{|l|l|l|}
\hline & male & female \\
\hline A & 22 & 19 \\
\hline B & 109 & 91 \\
\hline
\end{tabular}

Tab. 14 - Results of testing and test criteria. Source: author

\begin{tabular}{|l|l|}
\hline The level of significance & $\alpha=0,05$ \\
\hline Test criteria & $\chi^{2}=0,0097$ \\
\hline Table value & $\chi^{2}(1)=3,84$ \\
\hline
\end{tabular}

Based on the resulting test criteria $\chi^{2}=0.0097$ for independence, $\mathrm{H} 0$ is confirmed (table 14). This means that the irrational consumer choice in the case of perfect information in case of accidental death is independent in a view on whether it is man or woman (table 13).

H6: Irrational consumer choice in the case of perfect information is independent of client education.

Tab. 16 - Selecting the insurance in case of death divided by education. Source: author

\begin{tabular}{|c|c|c|c|}
\hline & PS & SS & HS \\
\hline A & 8 & 29 & 4 \\
\hline B & 27 & 134 & 37 \\
\hline
\end{tabular}

Tab. 17 - Results of testing and test criteria. Source: author

\begin{tabular}{|l|l|}
\hline The level of significance & $\alpha=0,05$ \\
\hline Test criteria & $\chi^{2}=2,4264$ \\
\hline Table value & $\chi^{2}(2)=5,991$ \\
\hline
\end{tabular}

Based on the resulting test criteria $\chi^{2}=2,4264$ for independence, H6 is comfirmed (table 16). This means that the choice of non-optimal variant is independent of the level of education (table 17).

\section{SUMMARY}

This article mapped consumer behavior in the choice of insurance. There was analyzed some factors of irrational behavior. The clients had to choose one of the insurance options in the questionnaire. The chart 1 showed, that most clients in the first stage of the decision process behaved rationally. Irrational choice, i.e. option A and B were voted by together 240 respondents, which is not a negligible number. The reasons for their choices were analyzed later through the following hypotheses.

H0:The choice of insurance against death is independent due to the income of a client.

H1:The choice of insurance against death is independent due to gender of a client.

H2: The choice of insurance against death is independent due to the level of education of a client. 
The results of analysis, of factors influencing the decision of the respondents, showed that the decision on the choice of insurance coverage option is not related to gender and level of education. One effect is the inclusion of respondents to a certain income groups. Clients belonging to the lowest and highest income groups analyzed would choose option $\mathrm{C}$ - it is therefore a rational decision, and the remaining respondents would choose the $\mathrm{B}$ variant. The fact of the respondents belonging to the highest income group can be explained by that, that they do not address the issue of price of insurance. For the lowest income group that cannot be said, and therefore the circumstances leading to the selection of this option should be subjected to further research.

The second group of those hypotheses was consisted by those, whose the main objective was to determine whether in the case of perfect information, the consumer decides rationally. This fact has been inferred from the hypotheses:

H3: The decision about changing the option of insurance, in relation with discount of the product is not affected by the original rational (option C) or irrational option (option A) of the client.

H4: The decision about changing the option of insurance, in relation with changing scope of benefits is not affected by the original rational (option C) or irrational option (option A) of the client.

Both hypotheses were confirmed. This means that change of decision about the choice of insurance options at a discount and to change the scope of insurance coverage is independent of whether the client initially chose rationally (option C) or irrationally (option A). Rational decision of autonomous systems in one situation does not endorse the model of rational consumer behavior.

The latest ranges of hypotheses are those that specify the circumstances of choice for the irrational option of product (the chosen options A and B) in relation to selected social factors.

H5: Irrational consumer choice in the case of perfect information is independent of the client's gender.

H6: Irrational consumer choice in the case of perfect information is independent of client level of education.

The results of hypothesis testing showed that irrational consumer choice in the case of perfect information in case of accidental death is independent of gender and education level. The results of the hypotheses are summarized in the following table 18. There are factors which affect the client's decision. Effective tools, which can attract customers, are discounts and the change of insurance cover. This attractiveness is strong enough to disrupt people's rational decision (see chapter "Rationally behaving consumer").

Tab. 18 - Factors influencing the decision. Source: author

\begin{tabular}{|c|c|c|}
\hline Social factors & $\begin{array}{c}\text { Factors influencing } \\
\text { the decision }\end{array}$ & $\begin{array}{c}\text { Factors without effect on } \\
\text { the decision }\end{array}$ \\
\hline & Income group & Age \\
\hline & $\mathrm{x}$ & Gender \\
\hline Factors of the insurance company & Discount & $\mathrm{x}$ \\
\hline & Insurance cover & $\mathrm{x}$ \\
\hline
\end{tabular}




\section{CONCLUSION}

The insurance market in the Czech Republic on the supply side is exposed to pressure for higher commissions for insurance intermediaries and lower margins calculated for the product. On the demand side, increasing demands for quality and service levels. One way to achieve higher profits is to gain knowledge capital from the consumer behavior.

Aim of this document was to present a specific research plan implemented, which aimed to map the irrational behavior of consumer choice of insurance products. The results of the research project showed that most consumers under the influence of certain factors act irrationally. These factors include media coverage of the causes of claims discount, offer extension of insurance coverage.

Report arose within specific research following grant project GAČR „Decision making in autonomous systems No. 402/09/0662.“

\section{References}

1. Blackwell, R. et al. (2001). Consumer Behavior. Orlando: Harcourt.

2. Bray, J. (2008). Consumer Behavior Theory: Approaches and Models [online]. Date [15.12. 2011]. Retrieved from: http://eprints.bournemouth.ac.uk/10107/1/Consumer_Behaviour_Theory__Approaches_\%26_Models.pdf

3. Budíková, M., Králová, M., \& Maroš, B. (2010). Priovodce qákladními statistickými metodami. Praha: Grada.

4. Daňhel, J. et al. (2006). Pojistná teorie. Praha: Professional publishing.

5. Ghouri, A.M., Khan, N.U.R., Siddqui, U.A., Shaikh, A., \& Alam, I. (2010). Determinants Analysis of Customer Switching Behavior in Private Banking Sector of Pakistan. Interdisciplinary journal of contemporary research in business, 2 (7), 96-110.

6. Koudelka, J. (2006). Spotřebni chováni a sementace trhu. Praha: VŠE.

7. Ravichandran, K., Bhargavi,K., \& Kumar, S.A. (2010). Influence of Service Quality on Banking Customers, International Journal of Economics and Finance, 2 (4), 126-132.

8. Loudon, D. L., et al. (1993). Consumer Behavior Concepts and Applications. US: McGraw Hill.

9. Marešová, P., \& Drahokoupil, J. (2011). Consumer Decision Making in the Area of Insurance Products in the Czech Republic Compared with other countries. In Urban sustainability, cultural sustainability, green development, green structures and clean car (48-55). Athens: World scientific and engineering academy and society.

10. Proença, J. F., Rodrigues, M.A., \& Amorim, R. J. L. (2009). SST and the consumer behavior in Portuguese financial services, International Journal on www/Internet, 5 (2), 181-192.

11. Richarme, M. (2005). Consumer Decision-Making Models, Strategies, and Theories, [online]. Date [14.1. 2012]. Retrieved from: www.decisionanalyst.com/Downloads/ConsumerDecisionMaking.pdf

12. Schiffman, L. G., et al. (2007). Consumer Behavior. New Jersey: Prentice Hall.

13. Solomon, M., et al. (2006). Consumer Behavior: A European Perspective. Harlow: Prentice Hall.

14. Thaler, R., H. (2000). From Homo Economics to Homo Sapiens, Journal of Economics Perspectives, 14 (2), 133-141. http://dx.doi.org/10.1257/jep.14.1.133 
15. Weisstein, E. W. (2012) Fisher's Exact Test. [online]. Date [14.5. 2012]. Retrieved from: http:// mathworld.wolfram.com/FishersExactTest.html

16. Zinkhan, G.M. (1992). Human Nature and Models of Consumer Decision Making. Journal of Advertising, 21 (4), 138-149.

\section{Contact information}

Ing. Mgr. Petra Marě̌ová, Ph.D.

Univerzita Hradce Králové

Fakulta informatiky a managementu

Katedra ekonomie

E-mail:petra.maresova@ubk.cr. 